\title{
Mechanical Properties of NiTi-Based Foam with High Porosity for Implant Applications
}

\author{
Ying Qiu ${ }^{1,2} \cdot$ Hao $\mathrm{Yu}^{1} \cdot$ Marcus L. Young ${ }^{1}$
}

Published online: 9 November 2015

(C) ASM International 2015

\begin{abstract}
In order to better understand NiTi-based shape memory alloy foams for implant applications, $\mathrm{Ni}_{40} \mathrm{Ti}_{50} \mathrm{Cu}_{10}$ foams were heat treated and then deformed under incremental and cyclic compression loading. After heat treatment, the microstructure consists of a $(\mathrm{Ni}, \mathrm{Cu}) \mathrm{Ti}$ matrix with small $(\mathrm{Ni}, \mathrm{Cu})_{4} \mathrm{Ti}_{3}$ precipitates and a large $\mathrm{Ti}_{2}(\mathrm{Ni}, \mathrm{Cu})$ secondary phase. The heat-treated $\mathrm{Ni}_{40} \mathrm{Ti}_{50} \mathrm{Cu}_{10}$ foam exhibits a two-step transformation, involving B19' $\rightarrow$ B19 and $\mathrm{B} 19 \rightarrow \mathrm{B} 2$ on heating and $\mathrm{B} 2 \rightarrow \mathrm{B} 19$ and $\mathrm{B} 19 \rightarrow \mathrm{B} 19^{\prime}$ on cooling, respectively. One $\mathrm{Ni}_{40} \mathrm{Ti}_{50} \mathrm{Cu}_{10}$ foam was compression loaded for 10 cycles at each subsequent strain level, i.e., 1, 2, 3, 4, 5, and $6 \%$ strain. In each set of compressive stress-strain loops, the maximum stress level decreases due to plastic damage accumulation and/or retention of transformed martensite. Cross-sectional images from micro-computed tomography were collected during compression loading, which shows very uniform deformation without severe structural damage even up to $5 \%$ strain. Localized deformation is visible at $6 \%$ strain.
\end{abstract}

Keywords Stress-strain $\cdot$ Mechanical behavior $\cdot$ NiTibased foam

This article is an invited paper selected from presentations at the International Conference on Shape Memory and Superelastic Technologies 2014, held May 12-16, 2014, in Pacific Grove, California, and has been expanded from the original presentation.

Marcus L. Young

marcus.young@unt.edu

1 Materials Science and Engineering, University of North Texas, Denton, USA

2 Mechanical and Energy Engineering, University of North Texas, Denton, USA

\section{Introduction}

NiTi-based shape memory alloys (SMAs) are excellent candidates for implant applications due to their unique shape memory effect and pseudoelasticity, good biocompatibility, high corrosion resistance, and relatively low stiffness as compared to other biomedical alloys [1-3]. By introducing porosity into NiTi-based SMAs, it is possible to tailor the stiffness and microstructure to more closely match that of bone as well as improve tissue and bone ingrowth [4, 5]. The addition of $\mathrm{Cu}$, which substitutes for $\mathrm{Ni}$ in NiTi SMAs, such as $\mathrm{Ni}_{40} \mathrm{Ti}_{50} \mathrm{Cu}_{10}$, improves the stability of the phase transformation temperatures responsible for the shape memory effect and pseudoelasticity (up to $8 \%$ reversible strain) and narrows the phase transformation hysteresis [6-12]. Heat treatments can be used to enhance the mechanical properties, increase the phase transformation temperatures, and likely decrease $\mathrm{Ni}$ release, and thus, decrease toxic, allergic, and carcinogenic effects [13] by forming $\mathrm{Ni}_{4} \mathrm{Ti}_{3}$ precipitates, which also improve the phase transformation recovery.

Bricknell et al. [7] showed that the substitution of $\mathrm{Cu}$ for $\mathrm{Ni}$ in NiTi SMAs decreases the lattice distortion needed to form the martensite phase from the austenite phase, while still maintaining the ordered $\mathrm{CsCl}$ type structure at high temperature. Gil et al. $[14,15]$ showed that NiTiCu SMAs exhibit a much more narrow stress hysteresis, based on transformation stresses, as compared to binary NiTi SMAs. Fatigue testing of NiTiCu SMA actuator springs were conducted by Grossmann et al. [16, 17]. They reported that the functional fatigue resistance of $\mathrm{NiTiCu}$ SMAs is strongly improved by the addition of $\mathrm{Cu}$. Sehitoglu et al. [18, 19] and Biscarini et al. [20] investigated the mechanical properties of $\mathrm{NiTiCu}$ single crystal SMAs under compression loading, and reported that the slip 
resistance increases when $\mathrm{Ni}$-rich precipitates are present. To date, the mechanical behavior of bulk NiTiCu SMA is well established [7, 14-19, 21-24]; however, few studies have focused on the effect of porosity on NiTiCu SMAs [25-28]. Goryczka et al. [26, 27] examined powder processing methods for producing homogenous $\mathrm{NiTiCu}$ SMAs. They found that porous NiTiCu SMAs show a similar martensite transformation behavior as compared to $\mathrm{NiTiCu}$ bulk materials. Porous NiTiCu SMAs can be optimized for implant applications due to the tunable stiffness, which can be tailored to match with the surrounding tissue or bone structure by controlling the porosity [9]. Young et al. [28] produced NiTiCu foams with $60 \%$ porosity by casting a bulk NiTiCu SMA into $\mathrm{SrF}_{2}$ salt preform and then dissolving away the $\mathrm{SrF}_{2}$ salt preform with an acid solution. In this earlier study, the method for producing cast-replicated $\mathrm{NiTiCu}$ foams was presented as well as the microstructure and compression loading/unloading data for seven consecutive loops at body temperature $(311 \mathrm{~K})$ for a $\sim 60 \%$ porous $\mathrm{NiTiCu}$ foam which was homogenized at $1173 \mathrm{~K}$ for $5 \mathrm{~h}$. These foams exhibited $4 \%$ recoverable strain and relatively low stiffness under single loading and unloading conditions at body temperature [28]. However, the mechanical behavior of these NiTiCu foams under cyclic loading conditions and the microstructural evolution after cyclic loading and unloading at room temperature have not been investigated. In the study presented here, a $76 \%$ porous NiTiCu foam was produced from the same method as presented in Young et al. [28], resulting in a martensitic SMA at room temperature. This NiTiCu foam was additionally heat treated to obtain austenite at room temperature. The mechanical response and microstructural evolution of this austenitic $\mathrm{NiTiCu}$ foam was further examined at room temperature with micro-computed tomographic $(\mu-\mathrm{CT})$ imaging during incremental and cyclic in situ compression loading and unloading. The combination of mechanical loading and imaging allows for analysis of both the macroscopic and microscopic mechanical behavior of the NiTiCu foam.

\section{Experimental}

$\mathrm{Ni}_{40} \mathrm{Ti}_{50} \mathrm{Cu}_{10}$ foams (referred to as $\mathrm{NiTiCu}$ foams throughout the paper) were prepared by a salt replication casting process $[28,29]$. The process involved the following steps: (1) $\mathrm{SrF}_{2}$ powders with $180 \mu \mathrm{m}$ to $355 \mu \mathrm{m}$ size were packed into an alumina crucible and sintering at $1673 \mathrm{~K}$ for $10 \mathrm{~h}$ under a vacuum with $10^{-4} \mathrm{~Pa}$ pressure, (2) a bulk NiTiCu SMA was then placed in an alumina crucible on top of an alumina spacer disc which was on top of the partially densified $\mathrm{SrF}_{2}$ preform, (3) the crucible with the bulk NiTiCu SMA, alumina spacer disc, and the porous
$\mathrm{SrF}_{2}$ preform was then heated under high vacuum to $1648 \mathrm{~K}$. After holding at this temperature for $1 \mathrm{~h}$, the chamber was then backfilled with Ar gas to a pressure of $1 \mathrm{~atm}$, which forced the fully melted NiTiCu SMA into the porous $\mathrm{SrF}_{2}$ preform, (4) the resulting $\mathrm{NiTiCu} / \mathrm{SrF}_{2}$ composite structure was then sectioned using an oil-cooled diamond wire saw (MTI Corporation, STX-202) into compression samples with approximate dimensions of $2.5 \times 2.5 \times 5.0 \mathrm{~mm}^{3}$, (5) the compression samples were ultrasonicated in an aqueous solution with $20 \%$ nitric acid for $2 \mathrm{~h}$ in order to remove the space holder $\left(\mathrm{SrF}_{2}\right.$ preform), and (6) the NiTiCu compression samples were then sealed in evacuated quartz capsules and homogenized at $1173 \mathrm{~K}$ for $5 \mathrm{~h}$, followed by water quenching, and then heat treated at $673 \mathrm{~K}$ for $8 \mathrm{~h}$ to improve the mechanical behavior by forming $\mathrm{Ni}_{4} \mathrm{Ti}_{3}$-like precipitates.

Differential scanning calorimetry (DSC) was conducted to study the phase transformation characteristics of the NiTiCu SMA foam using a Netzsch instrument (DSC 204 F1 Phoenix). DSC samples with a mass between 20 and $40 \mathrm{mg}$ were individually sealed in cold-weldable, lidded aluminum crucibles, and subsequently heated and cooled from 203 to $373 \mathrm{~K}$ at a heating/cooling rate of $10 \mathrm{~K} / \mathrm{min}$. The DSC samples were held at the maximum and minimum temperature for $3 \mathrm{~min}$ to reach thermal equilibrium. Scanning electron microscopy (SEM) with energy dispersive spectroscopy (EDS) was performed on a FEI instrument (FEI quanta 200 ESEM). Density measurement of the $\mathrm{NiTiCu}$ SMA foam was carried out on a Micromeritics Pycnometer (Accupyc II 1340). The porosity $(P)$ was calculated using the following equation:

$P=\left(1-\frac{\rho}{\rho_{\mathrm{B}}}\right) \times 100 \%$

where $\rho$ is the measured density of NiTiCu foam and $\rho_{\mathrm{B}}$ is the density of bulk NiTiCu, $6.5 \mathrm{~g} / \mathrm{cm}^{3}$ [21].

A Skyscan $1172 \mathrm{X}$-ray $\mu$-CT scanner was used to perform combined cyclic compression testing and 3D X-ray tomography. The engineering strain measurements were based on the crosshead displacement, which was corrected and verified by testing a Teflon sample with similar dimensions as that of the NiTiCu foam compression sample. 3D X-ray tomographic images of the NiTiCu foam sample were collected before compression and at compression up to $1,2,3,4,5$ and $6 \%$ strain, where 10 loading/unloading cycles were performed at each strain level. X-ray $\mu$-CT scanning was performed at a tube voltage of $100 \mathrm{kV}$ and a tube current of $100 \mu \mathrm{A}$ with an $\mathrm{Al}+\mathrm{Cu}$ filter. $\mathrm{X}$-ray radiographs were taken with an angular step of $0.4^{\circ}$ and compiled to create a reconstructed 3D structure of the as-compressed $\mathrm{NiTiCu}$ foam sample. About 860 radiographs with a pixel size of $4.95 \mu \mathrm{m}$ were obtained for each tomographic image. Image analysis 
softwares (NRecon, CTvox, and Dataviewer) were used to perform the $3 \mathrm{D}$ reconstruction and analysis.

\section{Results and Discussion}

Figure 1a-c shows cross-sectional X-ray radiographs of the porous NiTiCu SMA foam in the $\mathrm{X}^{-}, \mathrm{z}^{-}$, and $\mathrm{y}$-axes, respectively. Figure 1d shows the $3 \mathrm{D}$ reconstructed image of the porous NiTiCu SMA. These reconstructions were performed using NRecon software which confirms that the $\mathrm{SrF}_{2}$ salt has been completely removed. As illustrated in Fig. 1a-d, the pore pattern and structure of the porous
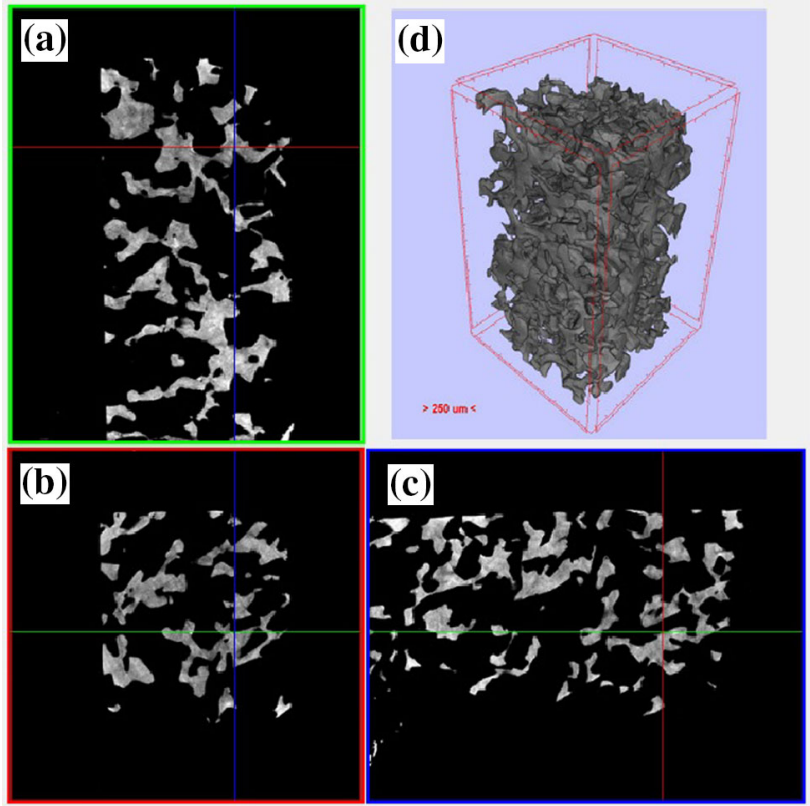

Fig. 1 Cross-sectional X-ray radiographs of the porous NiTiCu SMA foam for the a x-(green box), b z-(red box), and $\mathbf{c}$ y-axes (blue box) and d $3 \mathrm{D}$ reconstructed image of the porous NiTiCu SMA foam (Color figure online)
NiTiCu SMA foam sample after salt removal is readily visible and very uniform; however, most of the mass is centered on the nodes, which is a result of the geometry of the $\mathrm{SrF}_{2}$ particles and the salt replication processing. The density of the porous $\mathrm{NiTiCu}$ foam sample was measured to be $1.55 \mathrm{~g} / \mathrm{cm}^{3}$, corresponding to a porosity of about $76.2 \%$. This high porosity is also verified by the 3D reconstructed image of the porous $\mathrm{NiTiCu}$ foam (Fig. 1d). Similar structures have been observed in other metal foams prepared by this method [28-30]. As indicated in Fig. 1ac, the foam is fully interconnected, which is favorable to accommodate uniform compression deformation.

As illustrated in Fig. 2a, b, SEM images of the NiTiCu foam after heat treatment reveal a $(\mathrm{Ni}, \mathrm{Cu}) \mathrm{Ti}$ matrix with small $(\mathrm{Ni}, \mathrm{Cu})_{4} \mathrm{Ti}_{3}$ precipitates and a large dendritic $\mathrm{Ti}_{2}$ (Ni,Cu) secondary phase. Like the $\mathrm{Ti}_{2} \mathrm{Ni}$ phase in $\mathrm{NiTi}$ binary SMAs $[23,28]$, the $\mathrm{Ti}_{2}(\mathrm{Ni}, \mathrm{Cu})$ phase is brittle and thus detrimental to the shape memory effect and mechanical behavior [28]. This phase forms in a peritectic reaction in the NiTi matrix during the melting process $\left(1375^{\circ} \mathrm{C}\right.$, $1 \mathrm{~h}$, Ar gas) and is commonly stabilized by interstitial oxygen atoms $[28,31] .(\mathrm{Ni}, \mathrm{Cu})_{4} \mathrm{Ti}_{3}$ precipitates are the lenticular particles, which are the typical four variant $\mathrm{Ni}_{4}$ $\mathrm{Ti}_{3}$ precipitates morphology [32], shown distributed in Fig. 2b. The $(\mathrm{Ni}, \mathrm{Cu})_{4} \mathrm{Ti}_{3}$ phase corresponds to $\mathrm{Ni}_{4} \mathrm{Ti}_{3}$ phase in binary NiTi SMAs and forms in the NiTi matrix during the heat treatment process $\left(400{ }^{\circ} \mathrm{C}, 8 \mathrm{~h}\right)$. The formation of $\mathrm{Ti}_{2}(\mathrm{Ni}, \mathrm{Cu})$ and $(\mathrm{Ni}, \mathrm{Cu})_{4} \mathrm{Ti}_{3}$ phase affects the $\mathrm{Ni}$ content of the $(\mathrm{Ni}, \mathrm{Cu}) \mathrm{Ti}$ matrix, which in turn has an influence on the martensite transformation temperatures [33]. As shown in the SEM image in Fig. 3, EDS measurements were collected from 6 different regions. The EDS data for Fig. 3 are shown in Table 1, where the compositions of the various phases can be seen. The addition of $\mathrm{Cu}$ distorts the ratio of $\mathrm{Ni}$ to $\mathrm{Ti}$, however, it is not clear what the role of $\mathrm{Cu}$ is and how it affects the formation of $\mathrm{Ti}_{2}(\mathrm{Ni}, \mathrm{Cu})$ and $(\mathrm{Ni}, \mathrm{Cu})_{4} \mathrm{Ti}_{3}$ phases in this alloy.
Fig. 2 a SEM image and b detailed view of the same SEM image of NiTiCu SMA foam after heat treatment
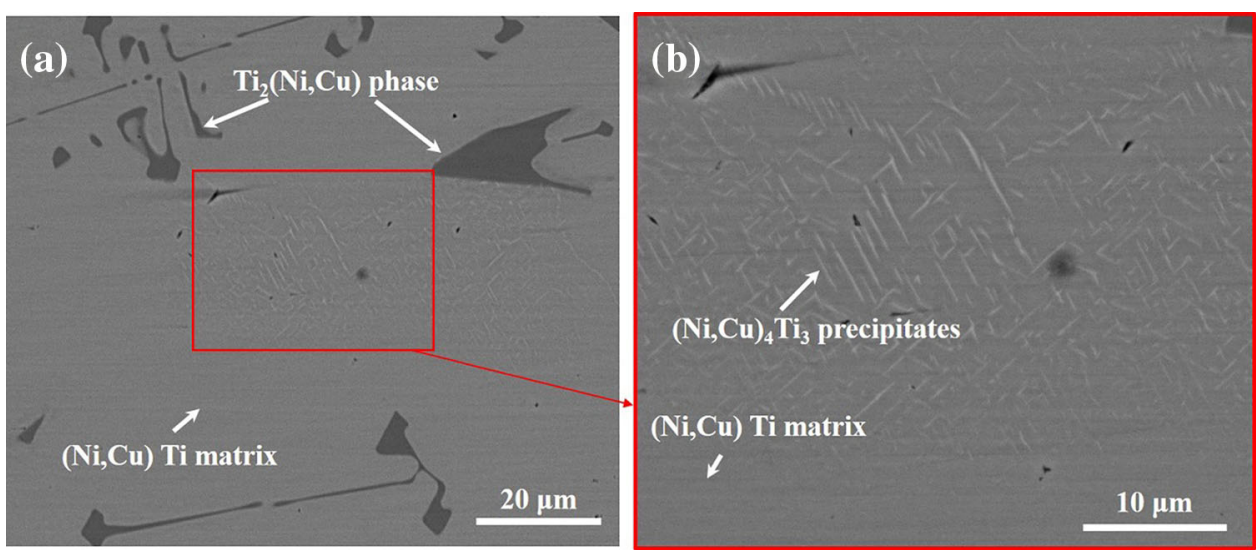
As indicated in Fig. 4, the DSC curves for the heattreated $\mathrm{NiTiCu}$ foam exhibit a two-step phase transformation below room temperature (298 K), which corresponds to $\mathrm{B} 19^{\prime} \rightarrow \mathrm{B} 19$ and $\mathrm{B} 19 \rightarrow \mathrm{B} 2$ on heating and $\mathrm{B} 2 \rightarrow \mathrm{B} 19$ and B19 $\rightarrow$ B19' on cooling, respectively, and indicate that the foam is fully austenitic at room temperature $(298 \mathrm{~K})$. The bulk NiTiCu SMA material exhibits a two-step transformation as well, but is fully austenitic above $\sim 348 \mathrm{~K}$. A similar $\mathrm{NiTiCu}$ foam with lower porosity ( $\sim 60 \%$ ) and no heat treatment is fully austenitic at body temperature $(311 \mathrm{~K})$ [28]. The heat treatment $(673 \mathrm{~K}$ for $8 \mathrm{~h}$ ) performed in this study was effective at lowering the transformation temperatures such that the NiTiCu foam is fully austenitic at room temperature. This additional heat treatment should result in the formation of $(\mathrm{Ni}, \mathrm{Cu})_{4} \mathrm{Ti}_{3}$ precipitates and this is confirmed in the SEM images shown in Fig. 2b, where more $(\mathrm{Ni}, \mathrm{Cu})_{4} \mathrm{Ti}_{3}$ precipitates are observed as compared to those observed in [28] without this heat treatment. If more $(\mathrm{Ni}, \mathrm{Cu})_{4} \mathrm{Ti}_{3}$ precipitates formed, one would expect to observe an increase in the transformation temperatures, as the $(\mathrm{Ni}, \mathrm{Cu}) \mathrm{Ti}$ matrix would be depleted of $\mathrm{Ni}$ [31]. However, the transformation temperatures are observed to decrease instead and a twostep transformation is observed rather than a 1-step transformation. It is unclear why this decrease occurred and why there is now a two-step transformation as opposed to a one-

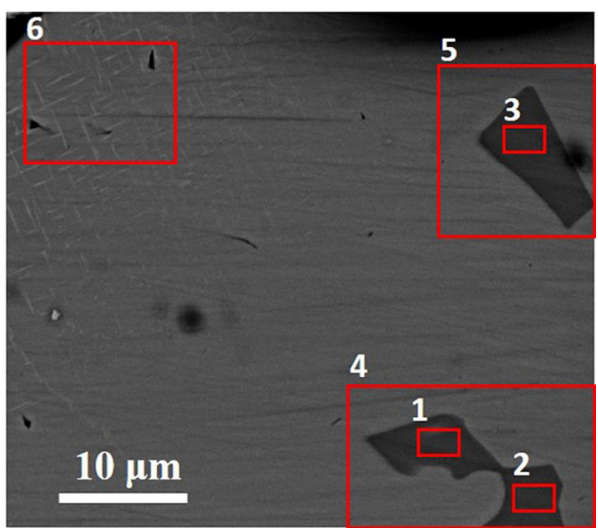

Fig. 3 SEM images of NiTiCu SMA foam after heat treatment (red boxes 1, 2, 3, 4, 5, and 6 corresponding to the regions in Table 1) (Color figure online) step transformation after heat treatment. Transformation temperatures can be lowered by precipitating more $\mathrm{Ti}_{2}$ $(\mathrm{Ni}, \mathrm{Cu})$, but this should not occur, because $\mathrm{Ti}_{2}(\mathrm{Ni}, \mathrm{Cu})$ is not likely to precipitate at the lower temperature heat treatment. It was not possible to determine if more $\mathrm{Ti}_{2}$ $(\mathrm{Ni}, \mathrm{Cu})$ was precipitated. Further complicating the situation is the fact that $\mathrm{Ti}_{2}(\mathrm{Ni}, \mathrm{Cu})$ precipitates can be stabilized by forming the $\mathrm{Ti}_{4}(\mathrm{Ni}, \mathrm{Cu})_{2} \mathrm{O}$ or $\mathrm{Ti}_{2} \mathrm{NiO}_{\mathrm{x}}$ phase [28, 31], although this oxidation should not affect the transformation temperatures as the matrix composition would not have changed with oxidation. This result is difficult to explain but may be due to heterogeneity from processing and nonequilibrium cooling conditions in the $\mathrm{NiTiCu}$ foam where more $\mathrm{Ti}_{2}(\mathrm{Ni}, \mathrm{Cu})$ could have formed and thus lowered the transformation temperatures.

As compared to the bulk material, the transformation temperatures are lower due to the decrease in $\mathrm{Ti}$ (or alternatively the increase in $\mathrm{Ni}$ ) in the $(\mathrm{Ni}, \mathrm{Cu}) \mathrm{Ti}$ matrix. This difference in transformation temperatures between the porous foam and the bulk material is the result of the formation of $\mathrm{Ti}_{2}(\mathrm{Ni}, \mathrm{Cu})$ and $(\mathrm{Ni}, \mathrm{Cu})_{4} \mathrm{Ti}_{3}$ precipitates during processing and heat treatment. $\mathrm{Ti}_{2}(\mathrm{Ni}, \mathrm{Cu})$ phase increases the $\mathrm{Ni}$ content in the matrix by pulling $\mathrm{Ti}$ out of the matrix, while $(\mathrm{Ni}, \mathrm{Cu})_{4} \mathrm{Ti}_{3}$ phase is apt to decrease $\mathrm{Ni}$ content by pulling $\mathrm{Ni}$ out of the matrix. The formation of these two phases affects the transformation temperatures by changing the matrix composition [31]. As compared to our previous $\mathrm{NiTiCu}$ foam [28] which was processed identically except that it was not heat treated after homogenization, the austenite start temperature $(\sim 293 \mathrm{~K})$ for the $\mathrm{NiTiCu}$ foam presented here is about $6 \mathrm{~K}$ lower than that previously reported value. As a result, the $\mathrm{NiTiCu}$ foam presented here is austenitic at room temperature and has slightly more $(\mathrm{Ni}, \mathrm{Cu})_{4} \mathrm{Ti}_{3}$ precipitates, which are also observable in Fig. $2 \mathrm{~b}$ as compared to Fig. $4 \mathrm{~b}$ in Young et al. [28].

The compressive loading and unloading curves for the $\mathrm{NiTiCu}$ SMA foam and the corresponding 3D reconstructed images are shown in Fig. 5. There is no apparent stress plateau in any of the stress-strain curves even when the strain is as high as $6 \%$, which is slightly different from the mechanical behavior of bulk NiTiCu SMA materials [18]. This difference is likely due to the high porosity,
Table 1 Phases identified by EDS analysis

\begin{tabular}{lllll}
\hline Region & $\mathrm{Ti}($ at.\%) & $\mathrm{Ni}($ at.\%) & $\mathrm{Cu}($ at.\%) & Possible phase \\
\hline 1 & 62.26 & 33.30 & 4.44 & $\mathrm{Ti}_{2}(\mathrm{Ni}, \mathrm{Cu})$ phase \\
2 & 62.37 & 33.60 & 4.03 & $\mathrm{Ti}_{2}(\mathrm{Ni}, \mathrm{Cu})$ phase \\
3 & 64.24 & 31.81 & 3.95 & $\mathrm{Ti}_{2}(\mathrm{Ni}, \mathrm{Cu})$ phase \\
4 & 47.22 & 43.00 & 9.78 & $(\mathrm{Ni}, \mathrm{Cu}) \mathrm{Ti}$ matrix and $\mathrm{Ti}_{2}(\mathrm{Ni}, \mathrm{Cu})$ phase \\
5 & 47.79 & 42.94 & 9.26 & $(\mathrm{Ni}, \mathrm{Cu}) \mathrm{Ti}$ matrix and $\mathrm{Ti}_{2}(\mathrm{Ni}, \mathrm{Cu})$ phase \\
6 & 46.74 & 38.21 & 15.05 & $(\mathrm{Ni}, \mathrm{Cu}) \mathrm{Ti}$ matrix and $\left(\mathrm{Ni}_{1} \mathrm{Cu}\right)_{4} \mathrm{Ti}_{3}$ precipitates \\
\hline
\end{tabular}


which results in the fracture of the thin struts or weak nodes before the critical transformation stress is reached [28]. For the first strain level, the sample was loaded to $1 \%$ strain and then unloaded to obtain one loop; the same operation was repeated 10 times. This data is not presented since it has considerable error associated with it due to the large step size $(0.01 \mathrm{~mm})$ of the loading stage and at that level it is only possible to collect at maximum 5 data points. After the specimen was compressed to 2, 3, 4 and $5 \%$ for 10 times, all the strains are fully recoverable in the range of the detector capacity of the load frame in $\mu$-CT. For $6 \%$ compression, about $1.5 \%$ strain did not recover after unloading. As shown in the 3D reconstruction images in Fig. 5, the majority of the structural features remain intact after multiple compression cycles. In general, the loops decrease in maximum stress with each subsequent

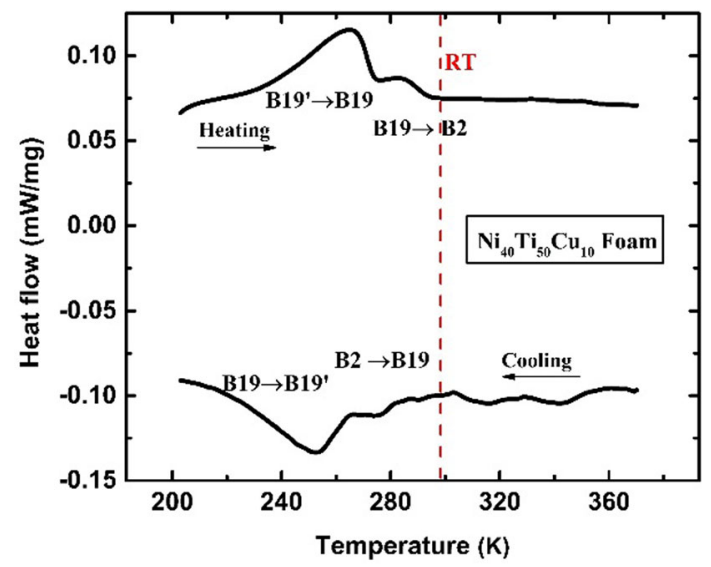

Fig. 4 DSC curves for the heat-treated NiTiCu SMA foam compression cycle. The maximum stress obtained is about $4 \mathrm{MPa}$ for $2 \%$ compression and that value increases to $8 \mathrm{MPa}$ for all subsequent compression strains (e.g., 3, 4, 5, and $6 \%$ strain). Therefore, the slope of the stress-strain curve decreases or in other words the macroscopic elastic modulus softens, because more thin struts are involved in the compression and are damaged as the strain increases, as shown in Figs. 5 and 6. The NiTiCu SMA foam appears fully elastic up to $5 \%$ strain macroscopically. This elasticity results from either a composite effect and/or is associated with the pseudoelastic effect. However, the onset of localized damage can be seen at $3 \%$ strain, which is likely due to the retention of the displacement or macroscopic damage at the top of the NiTiCu SMA sample, as observed microscopically in Figs. 5 and 6 using $\mu$-CT during in situ compression loading.

In order to examine the compression behavior internally within the NiTiCu SMA foam, a 2D cross-sectional image from each $3 \mathrm{D}$ reconstruction model which is parallel to the loading direction was examined at the end of each strain level after 10 cycles, as shown in Fig. 6. The majority of internal struts and nodes remain fully intact during compression cycling, while the height of the sample slightly decreases in the loading direction, which is expected after compression due to some localized plastic deformation. Some portions of the NiTiCu SMA foam moved down in the loading direction as the strain increased, (red ellipse labeled A in Fig. 6). This deviation in position is the direct result of damage accumulation. While some localized catastrophic damage near the top (blue box labeled B in Fig. 6) becomes visible, further visual inspection of these images reveals that a boundary can be defined as indicated by the red line in Fig. 6, below which structural
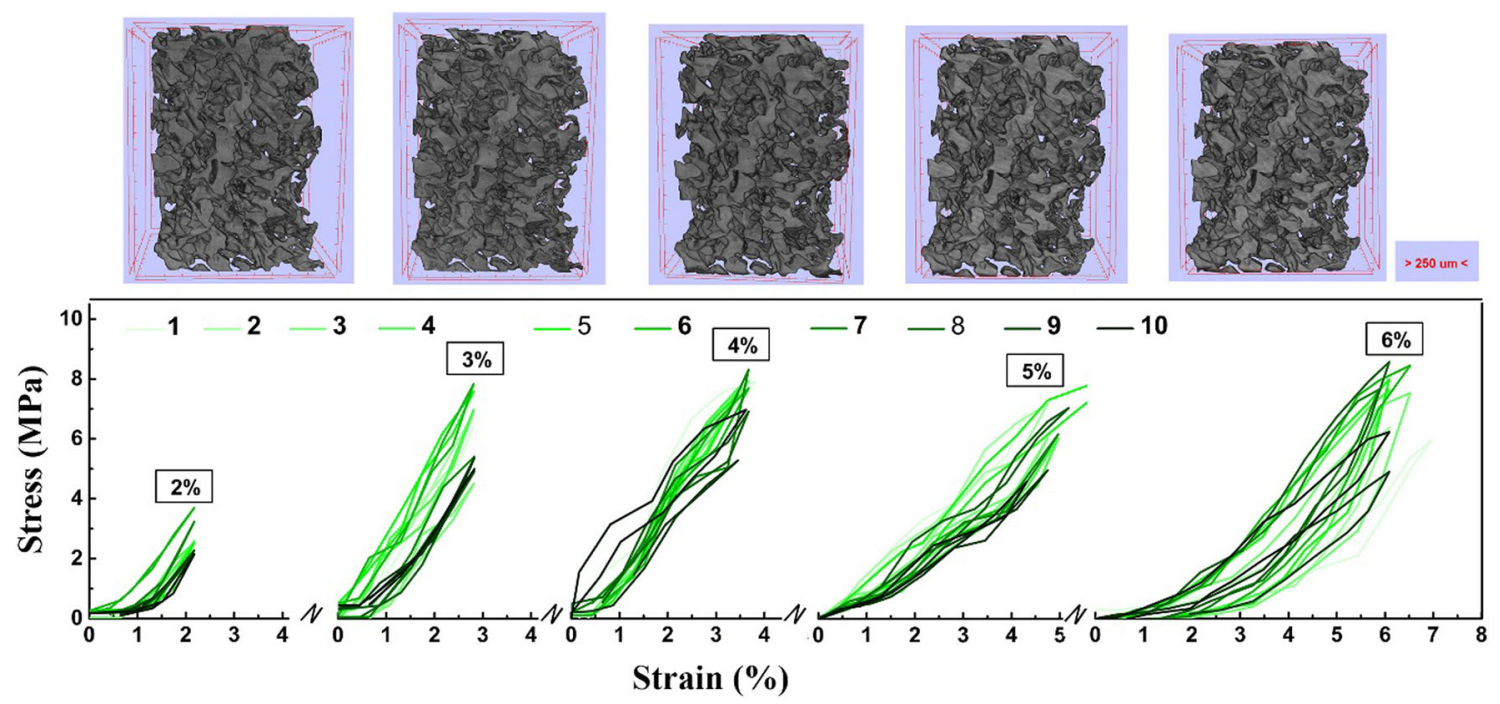

Fig. 5 2D cross-sectional images of the NiTiCu SMA foam parallel to the loading direction after compression to 2, 3, 4, 5, and $6 \%$ strain, respectively 

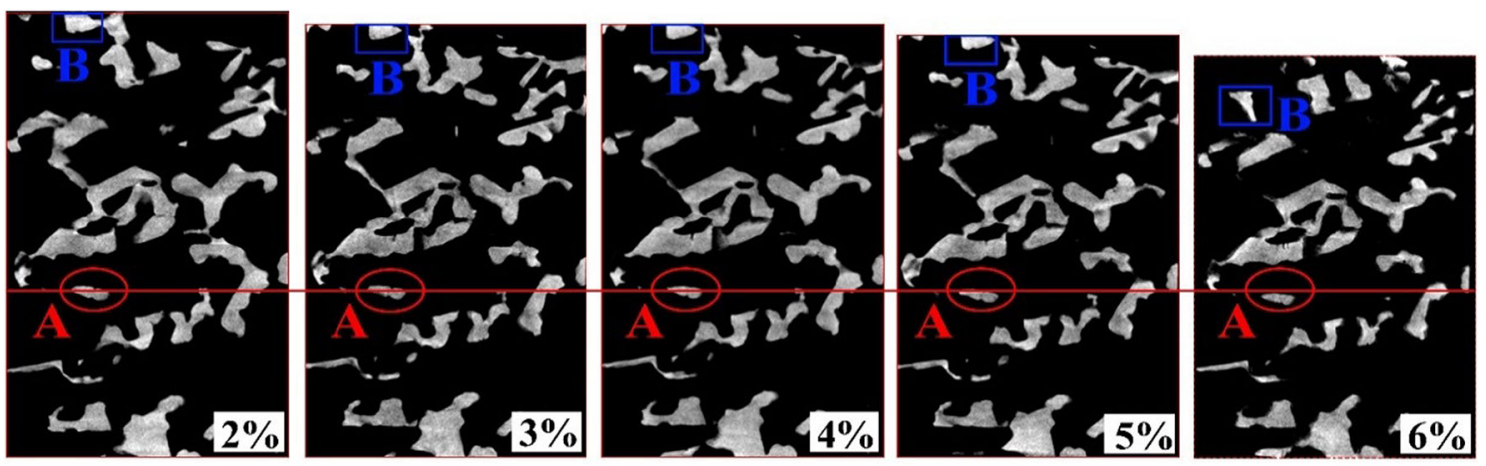

Fig. 6 Stress-strain curves from compression cycling for the NiTiCu SMA foam and corresponding 3D reconstructed X-ray $\mu$-CT images of the NiTiCu SMA foam after compression to $2,3,4,5$, and $6 \%$ strain, respectively

deformation is not apparent as compared with the region above the red line. This result is probably due to the relatively large struts and nodes which are interconnected and help to decentralize the external stress, thus preventing large plastic deformation or structural damage, or in other words, the stress remains localized during compression. However, the outer struts that lack interconnectivity in at least one direction tend to deform first, especially the thinner and, therefore weaker struts. As shown Fig. 5, the stress level remains constant at about $8 \mathrm{MPa}$ when the strain increases from 2 to $6 \%$ and this behavior is likely due to these weaker struts deforming in compression. At $6 \%$ strain, plastic deformation is apparent in both the stress-strain curves (Fig. 5) where some unrecoverable residual strains are present, and some large scale macroscopic visual damage is observed in Fig. 6, blue box labeled B.

\section{Conclusions}

In the present research, $\mathrm{Ni}_{40} \mathrm{Ti}_{50} \mathrm{Cu}_{10}$ SMA foams were heat treated and then deformed under incremental and cyclic compression loading conditions. The conclusions are as follows:

1. The $\mathrm{SrF}_{2}$ space holder was removed by ultrasonic vibration in a $20 \% \mathrm{HNO}_{3}$ aqueous solution for $2 \mathrm{~h}$ to create the porous NiTiCu SMA foam. After heat treatment, the $\mathrm{NiTiCu}$ foam consisted of a $(\mathrm{Ni}, \mathrm{Cu}) \mathrm{Ti}$ matrix with small $(\mathrm{Ni}, \mathrm{Cu})_{4} \mathrm{Ti}_{3}$ precipitates and a large dendritic $\mathrm{Ti}_{2}(\mathrm{Ni}, \mathrm{Cu})$ secondary phase. The $\mathrm{NiTiCu}$ SMA foam has a density of $1.55 \mathrm{~g} / \mathrm{cm}^{3}$ and a porosity of $76.2 \%$, which is higher than a NiTiCu SMA foam previously studied, likely due to a higher amount of metal dissolution during salt removal.

2. The $\mathrm{Ni}_{40} \mathrm{Ti}_{50} \mathrm{Cu}_{10}$ SMA foam exhibits a two-step phase transformation, which corresponds to B19' $\rightarrow$ B19 and
$\mathrm{B} 19 \rightarrow \mathrm{B} 2$ on heating and $\mathrm{B} 2 \rightarrow \mathrm{B} 19$ and B19 $\rightarrow$ B19' on cooling. The NiTiCu SMA foam here is austenitic at room temperature, with an austenite start temperature $(\sim 293 \mathrm{~K})$. While $(\mathrm{Ni}, \mathrm{Cu})_{4} \mathrm{Ti}_{3}$ precipitates are more abundant after heat treatment, the transformation temperatures are lower, which is unexpected. This result may be due to heterogeneity from processing and non-equilibrium cooling conditions in the $\mathrm{NiTiCu}$ foam where more $\mathrm{Ti}_{2}(\mathrm{Ni}, \mathrm{Cu})$ could have formed and thus lowered the transformation temperatures. The transformation temperatures are also about $50 \mathrm{~K}$ lower than bulk NiTiCu SMA materials.

3. The compressive stress-strain curves of the porous $\mathrm{Ni}_{40} \mathrm{Ti}_{50} \mathrm{Cu}_{10}$ SMA foam do not exhibit an apparent stress plateau even when the strain is as high as $6 \%$. Localized deformation results in relatively constant stress level when the strain increases from 2 to $6 \%$ and this response is either a composite effect and/or is associated with the pseudoelastic effect. Beyond $6 \%$ strain, both unrecoverable strains can be seen in the stress-strain curves as well as in the X-ray $\mu$-CT tomographic images, which is associated with plastic deformation.

Acknowledgments This research was financially supported by startup funds of Dr. Marcus L. Young. The authors would like to thank Colin Loeffler for the training of $\mu$-CT tomography scanning. The authors also would like to acknowledge the Center for Advanced Research and Technology at University of North Texas for access to the experimental facilities used for this study.

\section{References}

1. Andani MT, Shayesteh Moghaddam N, Haberland C, Dean D, Miller MJ, Elahinia M (2014) Metals for bone implants. Part 1. Powder metallurgy and implant rendering. Acta Biomater 10:4058. doi:10.1016/j.actbio.2014.06.025

2. Li B-Y, Rong L-J, Li Y-Y (1998) Porous NiTi alloy prepared from elemental powder sintering. J Mater Res 13:2847 
3. Fischer H, Vogel B, Welle A (2004) Applications of shape memory alloys in medical instruments. Minim Invasive Ther Allied Technol 13:248

4. Grummon DS, Shaw JA, Gremillet A (2003) Low-density opencell foams in the NiTi system. Appl Phys Lett 82:2727. doi:10. $1063 / 1.1569036$

5. Greiner C, Oppenheimer SM, Dunand DC (2005) High strength, low stiffness, porous $\mathrm{NiTi}$ with superelastic properties. Acta Biomater 1:705. doi:10.1016/j.actbio.2005.07.005

6. Nam TH, Saburi T, Nakata Y, Ki Shimizu (1990) Shape memory characteristics and lattice deformation in $\mathrm{Ti}-\mathrm{Ni}-\mathrm{Cu}$ alloys. Mater Trans JIM 31:1050

7. Bricknell R, Melton K, Mercier O (1979) The structure of NiTiCu shape memory alloys. Metall Trans A 10:693

8. Arciniegas M, Aparicio C, Manero JM, Gil FJ (2007) Low elastic modulus metals for joint prosthesis: tantalum and nickel-titanium foams. J Eur Ceram Soc 27:3391. doi:10.1016/j.jeurceramsoc. 2007.02.184

9. Bansiddhi A, Sargeant TD, Stupp SI, Dunand DC (2008) Porous NiTi for bone implants: a review. Acta Biomater 4:773. doi:10. 1016/j.actbio.2008.02.009

10. Barrabés M, Sevilla P, Planell JA, Gil FJ (2008) Mechanical properties of nickel-titanium foams for reconstructive orthopaedics. Mater Sci Eng C 28:23. doi:10.1016/j.msec.2007.02.001

11. Scalzo O, Turenne S, Gauthier M, Brailovski V (2009) Mechanical and microstructural characterization of porous NiTi shape memory alloys. Metall Mater Trans A 40:2061. doi:10. 1007/s11661-009-9906-1

12. Kockar B, Ozcan H, Cakmak S (2013) Shape memory behavior of Ni-rich NiTi foam with different porosity percentages. J Intell Mater Syst Struct 24:1131. doi:10.1177/1045389x12469450

13. Chen M-C, Wu S-K (2009) Surface analyses and biocompatibility study of $500 \&$ \#xB0;C oxidized Ni50Ti50 and Ni40Ti50Cu10 shape memory alloys. Surf Coat Technol 203:1715. doi:10.1016/ j.surfcoat.2009.01.012

14. Gil F, Solano E, Pena J, Engel E, Mendoza A, Planell J (2004) Microstructural, mechanical and citotoxicity evaluation of different NiTi and NiTiCu shape memory alloys. J Mater Sci Mater Med 15:1181

15. Gil F, Planell J (1999) Thermal efficiencies of NiTiCu shape memory alloys. Thermochim Acta 327:151

16. Grossmann C, Frenzel J, Sampath V et al (2008) Processing and property assessment of $\mathrm{NiTi}$ and $\mathrm{NiTiCu}$ shape memory actuator springs. Materialwiss Werkstofftech 39:499. doi:10.1002/mawe. 200800271

17. Grossmann C, Frenzel J, Sampath V, Depka T, Eggeler G (2009) Elementary transformation and deformation processes and the cyclic stability of NiTi and NiTiCu shape memory spring actuators. Metall Mater Trans A 40:2530
18. Sehitoglu H, Karaman I, Zhang X et al (2001) Deformation of $\mathrm{NiTiCu}$ shape memory single crystals in compression. Metall Mater Trans A 32:477

19. Sehitoglu H, Karaman I, Zhang X, Viswanath A, Chumlyakov Y, Maier H (2001) Strain-temperature behavior of NiTiCu shape memory single crystals. Acta Mater 49:3621

20. Biscarini A, Coluzzi B, Mazzolai G, Tuissi A, Mazzolai FM (2003) Extraordinary high damping of hydrogen-doped NiTi and $\mathrm{NiTiCu}$ shape memory alloys. J Alloys Compd 355:52. doi:10. 1016/s0925-8388(03)00267-6

21. Frantz-Rodriguez N, Bosseboeuf A, Dufour-Gergam E et al (2000) Composition and structure of $\mathrm{NiTiCu}$ shape memory thin films. J Micromech Microeng 10:147

22. Kotil T, Sehitoglu H, Maier HJ, Chumlyakov YI (2003) Transformation and detwinning induced electrical resistance variations in $\mathrm{NiTiCu}$. Mater Sci Eng A 359:280. doi:10.1016/s0921-5093(03)00365-4

23. Michaud V (2004) Can shape memory alloy composites be smart? Scripta Mater 50:249. doi:10.1016/j.scriptamat.2003.09. 016

24. Miller DA, Lagoudas DC (2000) Thermomechanical characterization of NiTiCu and NiTi SMA actuators: influence of plastic strains. Smart Mater Struct 9:640

25. Atiyah AA, Ali A-RKA, Dawood NM (2015) Characterization of $\mathrm{NiTi}$ and $\mathrm{NiTiCu}$ porous shape memory alloys prepared by powder metallurgy (Part I). Arab J Sci Eng 40(3):901-913

26. Goryczka T, Van Humbeeck J (2006) Characterization of a $\mathrm{NiTiCu}$ shape memory alloy produced by powder technology. J Achiev Mater Manuf Eng 17(1-2):65-68

27. Goryczka T, Van Humbeeck J (2008) NiTiCu shape memory alloy produced by powder technology. J Alloys Compd 456:194. doi:10.1016/j.jallcom.2007.02.094

28. Young ML, DeFouw JD, Frenzel J, Dunand DC (2012) Castreplicated $\mathrm{NiTiCu}$ foams with superelastic properties. Metall Mater Trans A 43:2939. doi:10.1007/s11661-011-1060-x

29. Brothers AH, Scheunemann R, DeFouw JD, Dunand DC (2005) Processing and structure of open-celled amorphous metal foams. Scripta Mater 52:335. doi:10.1016/j.scriptamat.2004.10.002

30. San Marchi C, Mortensen A (2001) Deformation of open-cell aluminum foam. Acta Mater 49:3959

31. Frenzel J, George EP, Dlouhy A, Somsen C, Wagner MFX, Eggeler G (2010) Influence of $\mathrm{Ni}$ on martensitic phase transformations in NiTi shape memory alloys. Acta Mater 58:3444. doi:10.1016/j.actamat.2010.02.019

32. Michutta J, Somsen C, Yawny A, Dlouhy A, Eggeler G (2006) Elementary martensitic transformation processes in $\mathrm{Ni}$-rich $\mathrm{NiTi}$ single crystals with $\mathrm{Ni}_{4} \mathrm{Ti}_{3}$ precipitates. Acta Mater 54:3525

33. Khalil-Allafi J, Dlouhy A, Eggeler G (2002) $\mathrm{Ni}_{4} \mathrm{Ti}_{3}$-precipitation during aging of NiTi shape memory alloys and its influence on martensitic phase transformations. Acta Mater 50:4255 